\title{
Retrospectiva
}

\section{Comunicação e discurso}

FIGARO, R (Org.). Comunicação e Análise do Discurso. 1. ed., $1^{\text {a }}$ reimpressão. São Paulo: Contexto, 2013.

Vicentônio Regis do Nascimento Silva* Daniele Trevelin Donato ${ }^{* *}$

O que é um texto? O que é um discurso? Como se constroem os sentidos? Quais as diferenças entre enunciado e enunciação? Como se desenvolve e o que é Análise do Discurso? Quando surgiram a polifonia e a dialogia? Como se elabora o sentido? Como se organiza o espaço discursivo? Como podemos analisar e diferenciar o real do ficcional, a história da literatura? Eis algumas das perguntas norteadoras de Comunicação e análise do discurso, obra organizada por Roseli Figaro, professora do Programa de Pós-Graduação em Ciências da Comunicação da Universidade de São Paulo - USP. Resultado de artigos expostos em seminários na Escola de Comunicação e Artes da USP/ I Ciclo de Estudos: Comunicação, Análise de Discurso e Atividade Linguageira, possui o objetivo de apresentar linhas teóricas na compreensão da Análise do Discurso (AD), aplicando-as aos textos jornalísticos, publicitários, literários, políticos, iconográficos.

Já na introdução, a organizadora esclarece que a linguagem verbal é objeto privilegiado de estudo da comunicação, diferenciando os conceitos de Texto (tecido confeccionado por autor que, transformado em discurso, entra no sistema de comunicação), Enunciado (criado por um sujeito historicamente situado, proveniente de um enunciador e fruto da enunciação) e Discurso (efeito de sentido construído no processo de interlocução).

Helena Nagamine Brandão - autora do primeiro capítulo, “Conceitos e fundamentos Enunciação e construção do sentido” - dedica-se à Análise do Discurso de linha francesa sob a ótica da enunciação. Segundo suas pesquisas, o discurso: 1) ultrapassa o nível gramatical/linguístico, valorizando os elementos extralinguísticos, condicionadores de sua

\footnotetext{
${ }^{*}$ Doutorando em Letras/Estudos Literários - Universidade Estadual de Londrina (UEL).

** Graduada em Letras - Universidade Estadual Paulista Júlio de Mesquita Filho (UNESP-Assis). Professora da rede pública/SP.
} 
produção; 2) produz enunciados concretos e efeitos de sentido; 3) elabora conhecimentos para “(...) produzir discursos adequados aos diferentes contextos de comunicação” (p.20).

Surgida na década de 1960, a Análise do Discurso debruça-se inicialmente sobre conteúdos políticos. Não se restringe a aspectos estritamente linguísticos, articulando as noções de Produção, Formação ideológica e Formação discursiva. Toda palavra e toda escrita inseremse em contextos ideológicos, reforçando a importância da compreensão e do uso da Base Linguística e do Processo Discursivo Ideológico, ferramentas para compreensão do sujeito do discurso. O conceito de heterogeneidade também integra a Análise do Discurso uma vez que na Formação Discursiva (FD) sobressai o sistema de dispersão em que interagem os discursos em relação de alteridade.

A autora então analisa quatro colaboradores do desenvolvimento da Análise do Discurso: Benveniste (a subjetividade funda-se no exercício da língua; construção do plano enunciativo do discurso em que a enunciação do locutor tem a intenção de influenciar o interlocutor), Bakhtin (tendo a interação como questão central, sua concepção de linguagem recai sobre o dialogismo, acentuando-se aspecto social na relação eu-tu; substitui-se o "eu” individualizado pelo “nós”), Authier-Revuz (“concepção do discurso assentada na característica heterogênea da linguagem e numa concepção de sujeito afetado pela divisão entre o consciente e o inconsciente. Enfim, ela questiona tanto uma concepção homogeneizadora da discursividade como a unicidade significante do sujeito" - p.35) e Ducrot.

Ducrot propõe a Teoria da Enunciação de caráter polifônico. Entre as modalidades que descrevem a enunciação (atribuição de sentido ao enunciado), destacam-se as relativas à argumentação, ao aspecto modal (enunciados de caráter informativo e expressivo) e ao sujeito ou autores eventuais da enunciação (sujeito: existe no mundo real; locutor: instância criada no discurso, equivalente ao narrador no texto literário; enunciadores: “corresponderiam a pontos de vista a expressarem um posicionamento em relação ao objeto observado a partir de uma perspectiva” - p. 39). Em um enunciado, pode existir mais de uma voz: se o Locutor é responsável pelas palavras, ao Enunciador atribuem-se os pontos de vista, criando-se o aspecto paradoxal da ironia.

Como uma teoria crítica da leitura, a contribuição da Análise do Discurso é mostrar que os modos de ver a realidade pela linguagem não são processos mecânicos de decodificação do sistema linguístico, mas é um processo dialógico em que o leitor, enquanto coenunciador, assume uma atitude 
responsiva dialogando com o texto, respondendo ao desafio de interpretação que impõe (p.42)

O capítulo seguinte, “Organização linguística do discurso - Enunciação e Comunicação”, de autoria de José Luiz Fiorin, discute duas teorias: as que desejam investigar a organização interna do discurso e as que pretendem estudar a historicidade textual. A ironia e a metáfora resultam das relações linguísticas e intertextuais. Segundo Benveniste, são instâncias de legitimação a pessoa (eu), espaço (aqui) e o tempo (agora). Instalam-se duas espécies de enunciados: 1) o que pode afastar o “eu”, equivalente à terceira pessoa na teoria literária; 2) o que insere o "eu” no interior do enunciado, criando a enunciação enunciativa, correspondente à primeira pessoa. O “eu” pressuposto denomina-se enunciador/autor. O “eu” instaurado no enunciado é o narrador, diferente do enunciador. O “eu” instituído na personagem que fala configura o interlocutor. Em algumas situações, o locutor pode tomar o lugar do narrador. Existem três níveis de sujeito: o autor, o narrador e o interlocutor. O "tu” do enunciador é o enunciatário, do narrador, narratário, do interlocutor, interlocutário.

Todos os textos - sejam eles na primeira ou na terceira pessoa - possuem efeitos de sentido. Alguns desses efeitos provocam a sensação de “objetividade”, que é uma “criação da linguagem” (p.58) utilizada para disfarçar opiniões, dificilmente identificáveis na superfície, porém descobertas em insinuações e subentendidos. A descoberta de insinuações e subentendidos pressupõe o domínio da historicidade - termo que não se atrela ao sentido histórico e aos contextos econômicos, políticos e sociais de uma época, mas à capacidade de o analista eleger elementos que o auxiliem na compreensão do discurso. Geralmente socorre-se ao dialogismo de Bakhtin para quem o discurso se constitui em oposição a outro, (re)tomando (novos) espaços ao longo da História. A substituição da primeira pessoa do singular em terceira pessoa do singular consiste em artifício de esvaziamento da subjetividade do indivíduo: em algumas situações a terceira pessoa deixa de lado o mortal/individual para se apossar do quase imortal/coletivo/público. Ao produzir um discurso, o orador cria e projeta uma imagem de si. Segundo Aristóteles, Ethos fomenta a imagem do caráter e das qualidades criadas no discurso.

“Construção coletiva da perspectiva dialógica - História e alcance teóricometodológico” traz, da pena de Beth Brait, as contribuições do Círculo de Bakhtin aos estudos da Análise Dialógica do Discurso (ADD). No ensino da gramática, de acordo com o teórico russo, a escola deve levar em conta as possibilidades lexicais e sintáticas da língua, oferecendo margens de escolha no momento da enunciação. As escolham indicam o ponto de vista do 
enunciador. Na ADD, observa-se a “(...) indissolúvel relação existente entre língua, linguagens, história e sujeitos” (p.84). Não interessa apenas o verbal, mas principalmente o visual e o verbovisual: "Há uma coisa muito importante ligada à leitura: o mesmo indivíduo transforma-se em leitor diferente, dependendo do tipo de leitura que está fazendo” (p.91).

Maria Cecília Souza-e-Silva, em “Concepção integrada de discurso - Discursividade e espaço discursivo", retoma as perspectivas de Maingueneau em "Gênese dos discursos", destacando-se: 1) a ideia de que o interdiscurso precede o discurso; 2) o tratamento do discurso a partir de um sistema de restrições/coerções globais. Das restrições/coerções globais surgem: a) competência discursiva; b) interincompreensão; c) prática discursiva; d) prática intersemiótica. Dois são os princípios estruturantes da gênese do discurso: a primazia do interdiscurso e a semântica global. A semântica se traduz por operação: o discurso-paciente (traduzido) por um discurso-agente (tradutor), dando vida à intercompreensão, que consiste na “(...) impossibilidade de compreensão de um discurso a partir de outro, de outra posição” (p.105). Cria-se um simulacro do outro a partir de seu discurso. A prática inter-semiótica abre possibilidades de análises nos conceitos de texto e enunciado, sendo este restrito aos textos linguísticos e aquele estendido às produções de práticas discursivas.

No último capítulo - "Discurso, ficção, realidade - A construção do 'real' e do 'ficcional'” - Maria Aparecida Baccega apresenta as ponderações entre realidade e ficcionalidade nas relações entre Literatura, História e Comunicação, ressaltando, desde as primeiras linhas, a diferença entre conhecimento e informação:

(...) cada domínio relaciona-se com os demais e isto é outra questão extremamente importante. O domínio da literatura se relaciona com o domínio do jurídico e este com o domínio das artes, e este com outros. O campo semântico do signo vai se recompondo, acrescentando semas ou subtraindo outros, mas sempre carregando consigo alguns semas que têm fôlego para percorrer os domínios. O que tem acontecido, e isto supõe um dos grandes temas da contemporaneidade, é que se toma um domínio separadamente, aprofunda-se e estuda-se, faz-se sua "análise”, sua "crítica”, fixando-se só em alguma parte da totalidade. É o que temos chamado de informação, isto não é conhecimento. O conhecimento prevê a capacidade de inter-relação dos domínios, inter-relação entre os dados, tendo como pano de fundo a totalidade daquela sociedade naquele momento histórico. De outro modo, ficamos apenas com os dados. (p. 120-121)

Palavra dada é palavra pronta. Palavra dando-se é uma palavra em construção. A instituição do sentido depende do lugar que a pessoa ocupa em sua produção. Na História, 
abrem-se oportunidades de novas fontes: abandona-se a exclusividade dos arquivos, imprimindo-se novas possibilidades de ser historiador e de se fazer História, especialmente por meio de interrogações dos silêncios. Nos diálogos entre domínios e discursos, o sujeito vai se moldando (p.132-133). Encerra a pesquisadora: “O que estamos propondo, enfim, é que o discurso do comunicador seja a conjunção dos discursos históricos e literários, com especificidades das quais os manuais de redação jamais darão conta” (p. 137).

Presente em nossas vidas, o discurso sempre transmite enunciados cujas enunciações se construirão a partir de fatores enumerados pelos diversos teóricos e pesquisadores anteriormente abordados, transmitindo informações que, já se percebe, jamais adquirirão tom neutro, sempre estarão repletas de artifícios com vistas a manipular o enunciatário.

Retrospectiva recebida em: 27.12.2014

Retrospectiva aprovada em: 24.05.2015 